\title{
"EXPANSÃO PARA QUEM?": UMA ANÁLISE DOS OBJETIVOS DO REUNI E DAS DIRETRIZES PARA A EDUCAÇÃO DO BANCO MUNDIAL
}

\section{Valéria Bonadia Marucchi Martoni1}

\section{Resumo}

Objetivou-se analisar a congruência entre o Programa de Apoio ao Plano de Reestruturação e Expansão das Universidades Federais e as diretrizes do Banco Mundial para a reestruturação do Ensino Superior. Foram analisados relatórios do órgão supraestatal e documentos vinculados ao Reuni. O programa, em sua pseudoconcreticidade, se apresenta como uma política social de ampliação do acesso ao ensino público, porém, após as análises empreendidas, verifica-se que este se pautou pelos ditames do capital, expressas nas diretrizes do BM, o que demonstra que tal expansão não deixou de promover o direcionamento do fundo público para a lógica reprodutiva do capital.

Palavras-chave: ensino superior; Reuni; Banco Mundial; fundo público; capital.

\section{"EXPANSION FOR WHOM?" : AN ANALYSIS OF REUNI OBJECTIVES AND GUIDELINES FOR THE EDUCATION OF THE WORLD BANK}

\section{Abstract}

The objective was to analyze the congruence between the Programme to Support the Plan of Restructuring and Expansion of Federal Universities and the World Bank guidelines for the restructuring of higher education. They were analyzed reports of supranational organ and documents related to Reuni. The program, in its pseudoconcreticity, presents itself as a social policy to increase access to public education, however, after the analyzes undertaken, it appears that this was marked by the dictates of capital, expressed in the World Bank guidelines, this shows that this

\footnotetext{
1 Mestre em Organizações e Desenvolvimento pelo Centro Universitário Franciscano do Paraná, Brasil. Admiistradora na Universidade Federal de Ouro Preto. E-mail: vmarucchi@gmail.com
} 
expansion has not ceased to promote the direction of public funds for reproductive logic of capital.

Keywords: higher education; Reuni; World Bank; public fund; capital.

\section{"EXPANSIÓN PARA QUIÉN ?" : UN ANÁLISIS DE OBJETIVOS DEL REUNI Y DE LA DIRECTRICES PARA LA EDUCACIÓN DEL BANCO MUNDIAL}

\section{Resumen}

Su objetivo es analizar la congruencia entre el Programa de Apoyo al Plan de Reestructuración y Expansión de las Universidades Federales y las directrices del Banco Mundial para la reestructuración de la educación superior. Fueron analizados informes del órgano supranacional y documentos relacionados a Reuni. El programa, en su pseudoconcreticity, se presenta como una política social para aumentar el acceso a la educación pública, no obstante, después de que el presente análisis, parece que este fue marcada por los dictados del capital, expresada en las directrices del Banco Mundial, lo que demuestra que esta expansión no dejó de promover la orientación de fondos públicos para la lógica reproductiva del capital.

Palabras clave: la educación superior; Reuni; Banco Mundial; fondo público; capital.

\section{Introdução}

Considerando a racionalidade econômica vigente, é possível observar a associação das políticas públicas com os interesses do capital, ou seja, a produção capitalista quanto mais se desenvolve, mais a lógica mercantil invade o conjunto das atividades e modos de pensamento que dinamizam as relações sociais. São diversas as transformações articuladas em prol do processo de produção e acumulação de capital. Nas áreas da educação, da saúde, do emprego, dentre outras, são estabelecidas as condições necessárias para o fortalecimento de tal processo, onde a promoção de políticas públicas concretiza a flexibilização e a desregulamentação, submetendo "todos os campos da vida social, sem exceção, [...] à valorização do capital privado" (CHESNAIS, 1996, p. 25).

Diante da atual divisão do trabalho, 'não existem fronteiras' para o movimento de produção do capital, (embora elas existam geográfica e 


\section{“EXPANSÃO PARA QUEM?": UMA ANÁLISE DOS OBJETIVOS DO REUNI E DAS DIRETRIZES PARA A EDUCAÇÃO DO BANCO MUNDIAL \\ Valéria Bonadia Marucchi Martoni}

politicamente) e o Estado desempenha, dentre outras, a função de garantir o movimento dessa produção mediante uma relativa submissão aos órgãos supraestatais. É possível observar tal subordinação efetuar-se pela mediação de instituições como o Banco Mundial e suas diretrizes, por exemplo, o conjunto de instruções do Banco condiciona as políticas educacionais, principalmente às direcionadas aos países em desenvolvimento, propondo a necessidade de diversificação da educação superior, preparação utilitária dos estudantes para o mercado, foco nos resultados, aprendizagem ao invés de educação. Seguindo essas diretrizes do BM reforça-se o caráter de mercadoria da educação e, assim o ensino torna-se um meio de disputa, através de processos de mercantilização, onde os investimentos estatais direcionados ao setor acabam não sendo em virtude de problemas e necessidades sociais da população. Isso parece não ser diferente para o Brasil, conforme aponta Silva, (1999, p. 297) sobre os projetos de reestruturação do ensino na década de 1990:

\footnotetext{
Negar a presença e a participação dos técnicos do Banco Mundial ficou insustentável. É visível a sua presença, especialmente na tomada de decisões traduzidas em atos e ações. [...] Resultado: o governo federal subscreveu a política dos gestores do Banco Mundial, e utiliza o MEC e os secretários de Educação para viabilizá-las na prática. Inicialmente, oferecem ajuda e cooperação e, em seguida, seduzem os recursos humanos e, se necessário, criam uma estrutura paralela para operacionalizar e fiscalizar o uso do dinheiro, o cumprimento com as metas e o pagamento regular dos empréstimos.
}

Por outro lado, importante destacar, como fizera Tragtenberg (2004) ao observar as considerações de Marx acerca do movimento dialético do real que a mesma realidade que cria a afirmação das possibilidades de incremento da valorização do valor também cria sua negação. Em outras palavras, as diretrizes constituídas pelos órgãos supraestatais (ainda que estes sejam constituídos por agentes de determinados Estados) condicionam as políticas educacionais em direção aos interesses do capital, também podem gestar as condições concretas de negação das mesmas. Assim, esse movimento de mercantilização da educação também cria seus movimentos de negação, a confirmação dessa possibilidade é visualizada nas críticas que diversos setores da comunidade acadêmica realizaram ao Programa Universidade para Todos, à Lei de Inovações Tecnológicas, às Parcerias Público Privadas, etc., (ANDES, 2007).

Em resposta as críticas, o governo brasileiro responde com o conhecido Programa de Apoio ao Plano de Reestruturação e Expansão das Universidades Federais (Reuni). Assim, pelo menos na imediaticidade do real, o Reuni atendeu a demanda da comunidade universitária no que tange ao investimento nos institutos federais de educação superior. Comunidade que, pelo menos em suas instituições representativas mais 


\section{“EXPANSÃO PARA QUEM?": UMA ANÁLISE DOS OBJETIVOS DO REUNI E DAS DIRETRIZES PARA A EDUCAÇÃO DO BANCO MUNDIAL \\ Valéria Bonadia Marucchi Martoni}

combativas (Andes, Une) defendem um ensino "público, gratuito e de qualidade". A gratuidade defendida coloca-se, portanto em oposição ao processo de mercantilização.

Nesse sentido, uma indagação se impôs, qual seja: estaria o Reuni sendo um instrumento de negação da submissão do Estado às diretrizes de instituições supraestatais? Em outras palavras, é possível pensar no Reuni enquanto uma forma de resistência do Estado brasileiro em busca de sua autonomia e do atendimento dos interesses de sua população em detrimento dos interesses do capital que são mediados por instituições superestatais como a já referida? Essa pergunta norteou a elaboração do trabalho aqui apresentado que tem como objetivo analisar a congruência entre o Programa de Apoio ao Plano de Reestruturação e Expansão das Universidades Federais e as diretrizes do Banco Mundial para a reestruturação do Ensino Superior, verificando se aquele se processa enquanto um movimento de negação às diretrizes e, por isso, rumo a constituição de uma educação mais humanista ou se não passa de outra forma de mercantilizar a educação sem a necessidade de concedê-la à exploração de capitalistas privados.

Para atender esse objetivo, partiremos da explicitação sucinta acerca de outros estudos já desenvolvidos sobre a mercantilização da educação e sua relação com os interesses do capital, pois é a partir deles que os materiais produzidos pelo governo brasileiro e pelo BM serão cotejados. Trata-se de uma pesquisa de caráter qualitativo e exploratória que tem como método a análise documental. Os documentos que foram utilizados serão apresentados no item três desse texto, seção que antecede à apresentação da análise dos dados, item quatro e cinco, e nossas consideração finais, item seis.

\section{O Que Outros Autores Escreveram Sobre a Mercantilização da Educação?}

Para Chesnais (1996, p. 42), o triunfo da "mercadorização" é total, "[...] mais completo do que jamais foi em qualquer momento do passado". O autor se refere ao que Marx chamava de "fetichismo da mercadoria". Para Marx (2008, p. 92) o fetiche da mercadoria: "[...] consiste em encobrir as características sociais do próprio trabalho dos homens, apresentando-as como características materiais e propriedades sociais inerentes aos produtos do trabalho." A mercadoria acaba naturalizando e coisificando as relações sociais entre os homens, ou seja, as relações entre os homens parecem ser relações sociais entre coisas.

Segundo Marx (2008), o espetáculo é o fetichismo da mercadoria potencializado, em que tudo vira mercadoria. A lógica do capital pode ser entendida por seu movimento, que somente é viabilizado por grupos de 


\section{“EXPANSÃO PARA QUEM?": UMA ANÁLISE DOS OBJETIVOS DO REUNI E DAS DIRETRIZES PARA A EDUCAÇÃO DO BANCO MUNDIAL \\ Valéria Bonadia Marucchi Martoni}

pessoas a partir do trabalho abstrato: “[...] o capital não é, pois, uma força pessoal; é uma força social” (MARX; ENGELS, 1987, p. 13). Considerando que o valor de troca se apodera do valor de uso para o mercado e este se amplia globalmente, o capitalismo constituiu-se historicamente como o campo propício para todas as formas de produção, ampliação e giro do capital:

[...] historicamente, quando até a força de trabalho se converte em mercadoria, está posta a possibilidade de mercantilizar o conjunto das relações sociais - isto é: não somente de introduzir a lógica mercantil (compra e venda) em todas as relações econômico-materiais mas, também, de generalizá-la às outras relações sociais. (NETTO; BRAZ, 2008, p. 85).

É possível verificar que nesse cenário, todas as coisas tornam-se mercadoria em prol da defesa do capital e do aumento da mais valia. No contexto educacional não seria diferente embora, em geral, se manifeste de forma distinta.

Para Marx (2008, p. 416-417), “[...] o enriquecimento do trabalhador coletivo e, por isso, do capital em forças produtivas sociais realiza-se à custa do empobrecimento do trabalhador em forças produtivas individuais" e dessa forma "[...] as manufaturas prosperam mais onde mais se dispensa o espírito" (2008, p. 417). E, nesse sentido, Dangeville (1978, p. 10) indicou que o ensino hegemônico está voltado para o tecnicismo, aumentando-se a divisão do trabalho e um contexto onde " $[. .$. divide-se igualmente o homem, tendo todas as outras potencialidades intelectuais e físicas sacrificadas ao aperfeiçoamento de uma atividade única" (DANGEVILLE, 1978, p. 10), ocorrendo uma separação entre o saber e o pensar.

Harvey (1992, p. 151) apontando especificamente para a educação superior, verifica as "[...] transições de muitos sistemas universitários do mundo capitalista avançado de guardiões do conhecimento e da sabedoria para produtores subordinados de conhecimento a soldo do capital corporativo" (HARVEY, 1992, p. 151).

Nos deparamos com inúmeras reformas destinadas ao ensino no país, que não atendem aos interesses da sociedade em geral, mas sim de pequenos grupos, como é o caso do PROUNI. Conforme aponta Lima (2005, p. 135), ao longo nos anos 90

[...] desencadeia-se uma ampliação do espaço privado, tanto nas atividades diretamente ligadas à produção econômica, como no campo dos direitos sociais historicamente conquistados pelas lutas da classe trabalhadora, o que gera um aprofundamento no processo de mercantilização da educação.

No cenário das Universidades, Tragtenberg (2004, p. 15) demonstrou que "[...] a universidade tende cada vez mais à adaptação indiscriminada a quaisquer pesquisas a serviço dos interesses econômicos hegemônicos". 


\title{
“EXPANSÃO PARA QUEM?": UMA ANÁLISE DOS OBJETIVOS DO REUNI E DAS DIRETRIZES PARA A EDUCAÇÃO DO BANCO MUNDIAL \\ Valéria Bonadia Marucchi Martoni
}

Segundo o autor, passamos por um processo de desestruturação das universidades em que, os efeitos da dominação, se fazem sentir, entre outras características, pelo afastamento entre 'fazer' e 'pensar', pois: “O pensamento está fundamentalmente ligado à ação" (TRAGTENBERG, 2004, p. 17). Assim sendo, o ideal clássico de universidade, voltada para a pesquisa, a difusão da cultura, uma visão crítica da totalidade, entram em colapso, pois “[...] a separação entre 'fazer' e 'pensar' se constitui numa das doenças que caracterizam a delinqüência acadêmica - a análise e a discussão dos problemas relevantes do país constituem um ato político, constituem uma forma de ação, inerente à responsabilidade social do intelectual"' (TRAGTENBERG, 2004, p. 18). E ainda:

\begin{abstract}
A delinqüência acadêmica caracteriza-se pela existência de estruturas de ensino em que os meios (técnicas) se tornam fins, os fins formativos são esquecidos; a criação do conhecimento e sua reprodução cedem lugar ao 'controle' burocrático de sua produção como suprema virtude, em que 'administrar' aparece como sinônimo de vigiar e punir - o professor é controlado mediante os critérios visíveis e invisíveis de nomeação; o aluno, mediante os critérios visíveis e invisíveis de exame. Isso resulta em escolas que se constituem em depósitos de alunos, como diria Lima Barreto em 'Cemitério de vivos' (TRAGTENBERG, 2004, p. 18).
\end{abstract}

Sabemos que o foco das instituições de ensino deveria estar voltado para a melhoria das condições de vida e não para atender majoritariamente os interesses de determinados grupos, porém o mercado universitário compreende atualmente grandes oportunidades "[...] na qual os critérios lucrativos da empresa privada funcionarão para a formação das fornadas de 'colarinhos brancos' rumo às usinas, aos escritórios e às dependências ministeriais” (TRAGTENBERG, 2004, p. 12).

\footnotetext{
É possível verificar que nesse cenário, todas as coisas tornam-se mercadoria em prol da defesa do capital e do aumento da mais valia. No contexto educacional não seria diferente embora, em geral, se manifeste de forma distinta. De um lado o Estado direciona os programas ao acúmulo de capital pelas instituições privadas de ensino e, do outro, baixos recursos são destinados ao setor público(TRAGTENBERG, 2004, p. 12).
}

Ressaltamos aqui, conforme Leher e Lopes (2008), que o ensino superior no país está submetido à ampliação e reprodução do capital, de modo que os sistemas educacionais foram submetidos a profundos processos de privatização, com a expansão da educação superior pela via privada, e o início, nas instituições públicas, de uma tendência - cada vez mais dominante - de mercantilização do trabalho docente, transformando as universidades em instituições mais parecidas com a de uma empresa privada e, é nesse sentido que se torna necessária uma análise do Reuni 


\section{“EXPANSÃO PARA QUEM?": UMA ANÁLISE DOS OBJETIVOS DO REUNI E DAS \\ DIRETRIZES PARA A EDUCAÇÃO DO BANCO MUNDIAL \\ Valéria Bonadia Marucchi Martoni}

dentro desse processo, atividade que intentamos fazer por meio do método de análise documental, como será exposto a seguir.

\section{Método}

O método que irá fundamentar o trabalho tem como eixo o Materialismo Histórico e Dialético. Parte-se do princípio que os fatos sociais não podem ser analisados isoladamente da conjuntura histórica, social e econômica, sem a devida observação das relações sociais estabelecidas no processo de produção da vida material. O método pode ser compreendido como "[...] um procedimento epistemológico, na medida em que ele define como o conhecimento é produzido, sistematizado e transmitido" (FARIA, 2011, p. 01), sendo que as técnicas são complementares aos métodos. Para a análise, compreensão e explicação do objeto de estudo, o método constitui-se como orientação fundamental, com a possibilidade do alcance explicativo da realidade para além dos seus aspectos aparentes, cada qual com suas particularidades e possibilidades de abarcar a realidade em sua essência. Lembrando que, conforme mencionado, a aparência que queremos superar é imediaticidade do Reuni enquanto um movimento de negação de distanciamento das diretrizes das instituições supraestatais. Para tanto, a pesquisa será embasada em um estudo qualitativo, sendo que a base teórica fornecerá os elementos necessários para a compreensão da totalidade concreta do ente empírico selecionado.

Como método de coleta e análise de dados, será utilizada a análise documental, pois como defende Corbetta (2007, p. 397) “Os relatórios do governo são uma importante evidência do estudo na base das políticas públicas". Ainda para o autor, "[...] um documento é definido como qualquer material que fornece informações sobre um determinado fenômeno social que existe para além da ação do investigador e [...] são produzidos por instituições ou pelos indivíduos no contexto de suas funções institucionais" (CORBETTA, 2007, p. 403).

Os documentos selecionados para essa pesquisa estão descritos nos dois grupos abaixo, conforme instituição que os produziram.

Banco Mundial, análise dos seguintes relatórios:

- Aprendizagem para Todos. Estratégia 2020 para a Educação do Grupo Banco Mundial. Resumo Executivo (2011);

- Construindo sociedades do conhecimento: novos desafios para a educação terciária (2002);

- Educação permanente na economia global do conhecimento: desafios para os países em Desenvolvimento (2003).

Governo Brasileiro: 
- Programa de Apoio a Planos de Reestruturação e Expansão das Universidades Federais (REUNI)

Os dados coletados sofreram uma análise descritivo-qualitativa amparada pelo quadro teórico. Em consonância com o método epistemológico, não cabe ao trabalho apresentar soluções concluídas ao estudo, mas, sim, contribuir com o debate sobre as efetivas ações do Estado Capitalista.

\section{O Caráter das Diretrizes do Banco Mundial}

O Banco Mundial, doravante BM, realiza financiamentos para projetos no Brasil com vistas ao desenvolvimento econômico e social desde 1949 e, assim, tal como em outros países por ele financiados, o Brasil vêm seguindo as orientações estratégicas promovidas pelo Banco. No campo educacional, as políticas têm sido intensas, pois as alterações no modelo de organização da produção tornaram necessárias algumas mudanças, principalmente, no que se refere à formação de mão de obra.

As reformas educacionais nos termos do BM demonstram a transformação da produção de pesquisa, pois, reforçar os sistemas educacionais significa alinhar o governo, a gestão de escolas e professores às regras de financiamento e aos mecanismos de incentivo, com os objetivos do programa do referido Banco, estabelecendo um ciclo de retorno entre o financiamento (incluindo a ajuda internacional) e os resultados (BANCO MUDIAL, 2011). Nas reformas educacionais por ele propagadas, a aprendizagem se relaciona com a competitividade, conforme o último relatório produzido pelo $\mathrm{BM}$ onde são apontadas as estratégias para a educação até 2020:

[...] o aumento impressionante de novos países de rendimento médio tem intensificado o desejo de muitas nações de aumentar a sua competitividade mediante a criação de novas forças de trabalho capacitadas e ágeis. Há um outro conjunto de alterações que é tecnológico: avanços incríveis nas tecnologias de informação e comunicação (TICs) e outras tecnologias estão a mudar os perfis dos empregos requeridos pelos mercados de trabalho, ao mesmo tempo a oferecer possibilidades de aprendizagem acelerada e melhor gestão dos sistemas de educação (BANCO MUNDIAL, 2011, p. 12).

Se a manutenção do sistema está necessariamente ligada ao trabalho e depende da expansão dos processos produtivos, os quais estão baseados na criação e renovação da força de trabalho, a aprendizagem acelerada está atrelada à "agilidade que a competitividade impõe", sendo que esse processo determina cada vez mais as políticas e ações empreendidas para a reestruturação do ensino superior. 


\section{“EXPANSÃO PARA QUEM?": UMA ANÁLISE DOS OBJETIVOS DO REUNI E DAS DIRETRIZES PARA A EDUCAÇÃO DO BANCO MUNDIAL \\ Valéria Bonadia Marucchi Martoni}

Em 2002, o BM publicou um relatório intitulado "Construindo a Sociedade do Conhecimento: Novos Desafios para o Ensino Superior", o qual descreve a importância do ensino superior para o desenvolvimento da economia mundial. Conforme tal documento, o ensino superior exerce uma "influência direta sobre a produtividade nacional" (BANCO MUNDIAL, 2002, p.20), e determina consideravelmente os padrões de vida e capacidade de um país para competir na economia global. Com isso, o BM ressalta a necessidade de obter melhores índices educacionais, uma vez que o crescimento do país poderá estar cada vez mais relacionado com a obtenção de números mais expressivos (de que?) que levaria a uma melhoria da imagem diante dos órgãos supraestatais.

A mais recente publicação do BM, com o lançamento de uma estratégia para os próximos 10 anos, possui como objetivo "investir em conhecimentos e competências para promover o desenvolvimento", requerendo novas reformas educacionais dos países em desenvolvimento. Para alcançar os objetivos do novo plano, intitulado "Aprendizagem para Todos", canaliza-se os seus esforços para a educação em duas vias estratégicas: reformar os sistemas de educação em nível dos países e construir uma base de conhecimento de alta qualidade para reformas educacionais em nível global (BANCO MUNDIAL, 2011). No início da publicação, pode-se verificar:

\footnotetext{
A impressionante ascensão dos países de renda média, liderada

pela China, Índia e Brasil intensificou o desejo de muitas nações de aumentar a sua competitividade mediante $o$ desenvolvimento de forças de trabalho mais capacitadas. Os avanços tecnológicos estão a mudar os perfis e as qualificações profissionais e, ao mesmo tempo, a oferecer possibilidades de aprendizagem acelerada. Os níveis implacavelmente elevados de desemprego, especialmente entre os jovens, ressaltaram a incapacidade dos sistemas de educação para formar jovens com as competências corretas para o mercado de trabalho (BANCO MUNDIAL, 2011, p. 04).
}

O relatório aponta que o aumento do desemprego está associado com o sistema educacional desviando da discussão sobre a incapacidade do capital de gerar postos de trabalho para todos, ou seja, desconsideram-se os processos sempre crescentes de se tentar maximizar as taxas de mais valia a partir de investimentos em capital constante. Nesse sentido, é preciso compreender alguns elementos sobre o papel do Estado nas reformas educacionais condicionadas pelas diretrizes supraestatais, pois conforme relatórios do BM, o que torna um país competitivo é a qualificação de sua mão de obra e não necessariamente o domínio para o desenvolvimento da tecnologia e assim o último deve concentrar-se na "base de conhecimento de alta qualidade", sendo essa gerida pelos "países já desenvolvidos". 


\section{“EXPANSÃO PARA QUEM?": UMA ANÁLISE DOS OBJETIVOS DO REUNI E DAS \\ DIRETRIZES PARA A EDUCAÇÃO DO BANCO MUNDIAL \\ Valéria Bonadia Marucchi Martoni}

Aos países em desenvolvimento, além de fornecer mão de obra qualificada e barata, resta ainda disponibilizar outras vantagens comparativas, como: isenções e incentivos fiscais, desorganização política dos trabalhadores, desregulamentações. Em suma, no centro das preocupações de países como o Brasil deve estar a qualificação para operar os meios de produção, sendo que, quanto mais qualificados forem os trabalhadores para a atuação em nível operacional, mais as empresas buscam novos territórios para instalar seus parques produtivos.

O relatório, ainda, aponta que o desemprego está associado à incapacidade do sistema educacional e, assim, desloca a discussão sobre o limite do sistema capitalista de absorver mão de obra, tal como abordado. A questão essencial que não pode ser evidenciada é o seu pressuposto para a produção de mais valia, que tem como um de seus mecanismos a introdução de tecnologia poupadora de força de trabalho. Conforme lembra Marx, em O Capital, a inovação tecnológica é poupadora de trabalho vivo, mas não de trabalhadores. Assim, destacam-se dois pontos daquele pequeno trecho da publicação do BM.

1) os avanços tecnológicos citados pelo Banco alteram a qualidade da força de trabalho necessária ao capital e, de forma contingencial, há um desequilíbrio entre a oferta e a demanda, criando, assim, a necessidade de uma reestruturação na Educação. Não se trata de uma incapacidade do sistema educacional, mas de um movimento real de adequação entre a necessidade de trabalho vivo no interior do processo produtivo e o contingente das qualidades da força de trabalho que a classe trabalhadora tem que oferecer em determinado período de tempo. Sendo o sistema de educação o lócus onde esse estoque é atualizado, o que está em pauta não é a incapacidade de algo existente, mas a necessidade de alterações nele a fim de que haja na classe trabalhadora o conteúdo de força de trabalho necessário ao capital, qualidades que até antes da introdução de novas tecnologias não eram demandadas dos trabalhadores, portanto, não era foco de atenção do sistema educacional. Assim, a tal incapacidade do sistema educacional é responsável pelo que chamamos de desemprego conjuntural, diferente, portanto, do problema da incapacidade que tem o capital de prover a todos os trabalhadores a possibilidade de venderem sua força de trabalho, ou seja, não há reforma no sistema educacional que dê conta de resolver o problema do desemprego ${ }^{2}$ estrutural que se intensificou após a última reestruturação da produção, fato que nos leva a segunda consideração.

2) As reformas no sistema educacional demandas pelo BM, na prática, colaboram para a produção do desemprego estrutural e da redução do valor da força de trabalho. A qualidade da força de trabalho demandada

\footnotetext{
${ }^{2}$ Faz-se necessário considerar aqui o movimento global do capital e não deixar que os atuais índices de emprego mascarem a situação mundial do desemprego.
} 


\section{“EXPANSÃO PARA QUEM?": UMA ANÁLISE DOS OBJETIVOS DO REUNI E DAS DIRETRIZES PARA A EDUCAÇÃO DO BANCO MUNDIAL \\ Valéria Bonadia Marucchi Martoni}

pelas novas tecnologias permite a intensificação da concorrência entre os trabalhadores, de forma que se a maquinaria (tecnologia) já poupa força de trabalho, a concorrência intensifica a exploração dessa, aumentando a produtividade e fomentando a intensificação do desemprego estrutural. Ou seja, a solução indicada pelo BM para resolver o problema dos altos índices de desemprego, pode se tornar em médio prazo, a causa do problema. Dessa maneira, novamente, não se trata de uma incapacidade do sistema educacional, mas sim do modo capitalista de produção em absorver mão de obra e de gerar novos postos aos trabalhadores, justamente pela tendência em investimentos para a otimização da produção (capital fixo) em detrimento dos direcionamentos ao capital variável.

Força de trabalho qualificada, para o BM, parece ser apenas força de trabalho apta para ser intensamente consumida - e quanto mais cedo, melhor -, tendo em vista que o importante não é o quanto um trabalhador apreendeu para obter um diploma universitário, mas o quanto ele consegue ser produtivo: "No nível pessoal, embora um diploma possa abrir as portas para um emprego, são as competências do trabalhador que determinam a sua produtividade e capacidade para se adaptar a novas tecnologias e oportunidades" (BANCO MUNDIAL, 2011, p.03). E o documento continua informando? “[...] o crescimento, o desenvolvimento e redução da pobreza dependem dos conhecimentos e qualificações que as pessoas adquirem, não no número de anos que passaram sentados numa sala de aula" (BANCO MUNDIAL, 2011, p. 14).

Assim, a diretriz do BM centraliza na aprendizagem ao invés de fomentar a educação. O objetivo é o desenvolvimento de competências para atender as exigências dos capitais nacionais e internacionais, como vemos na afirmação do BM acerca da necessidade de reformas educacionais em nível global. Afinal, com a flexibilização dos capitais e as constantes transferências das plantas produtivas ao redor do mundo, é necessário que haja um amplo e global exército de reserva qualificado para atender às demandas de trabalho vivo. Além disso, o BM ao enfatizar a redução do tempo em sala de aula advoga a favor do crescimento daquele contingente que, uma vez considerado apto para o trabalho, apresenta-se enquanto concorrente, deprimindo o preço da mercadoria vendida, ou seja, a força de trabalho 'qualificada'. Não desconsideramos que a pobreza pode ser reduzida pelo aprendizado de uma profissão e ingresso no mercado de trabalho, mas destacamos que, em geral, trata-se da redução contingencial e não da mitigação do processo de pauperização que a classe trabalhadora está submetida.

A partir de uma primeira leitura de alguns documentos do BM, é possível observar suas associações com o processo de reformulação na educação superior, atendendo as necessidades de desenvolvimento do modo de produção capitalista. As análises das diretrizes propostas pelo $\mathrm{BM}$ revelam uma organização de estratégias ideológicas voltadas às 


\section{“EXPANSÃO PARA QUEM?": UMA ANÁLISE DOS OBJETIVOS DO REUNI E DAS DIRETRIZES PARA A EDUCAÇÃO DO BANCO MUNDIAL \\ Valéria Bonadia Marucchi Martoni}

políticas educacionais com vistas à produção do conhecimento científico direcionado à lógica empresarial. Nesse sentido, Mészáros (2008, p. 15) aponta:

A educação, que poderia ser uma alavanca essencial para a mudança, tornou-se instrumento daqueles estigmas da sociedade capitalista [...], tornou-se uma peça do processo de acumulação de capital e de estabelecimento de um consenso que torna possível a reprodução do injusto sistema de classes. Em lugar de instrumento da emancipação humana, agora é mecanismo de perpetuação e reprodução desse sistema.

\section{O Reuni e seu caráter ${ }^{3}$}

Em abril de 2007 o Reuni foi aprovado pelo Decreto 6096/07. Dentre outros objetivos, o programa pretende "[...] criar condições para a ampliação do acesso e permanência na educação superior, no nível de graduação" (BRASIL, 2007). Para ter acesso aos recursos destinados ao Reuni as universidades deviam criar um projeto de implementação ao programa com duração para cinco anos.

Para a compreensão do significado do Reuni, fez-se necessário uma averiguação a respeito das lutas em torno da questão da necessidade de ampliação das vagas em um dado momento da história. Pode-se constatar que o movimento de transformação do sistema de educação superior no país e o consequente surgimento do REUNI, dentre outros fatores, é partícipe do movimento decorrente da reforma universitária de 1968 (Lei $\left.\mathrm{n}^{\circ} 5.540 / 68\right)$, a qual buscava "[...] pelo menos, dois objetivos: o da diversificação e o de que cada instituição deverá repensar e redefinir seu caráter e sua vocação" (CATANI, 2002, p. 19).

Com a reforma universitária aprovada sob a Lei $n^{\circ} 5.540 / 68$ foi definido o modelo de instituição de ensino superior a ser desenvolvido no país, contemplando o sistema federal e privado (ALMEIDA, 2006). Essa reforma instaurada pelo regime militar foi responsável por medidas que mudaram alguns aspectos da universidade pública. E disso surgiram os incentivos aos aspectos quantitativos do sistema de ES, buscando maior rentabilidade com uma quantidade menor de recursos. Tal processo influenciou e determinou a organização das universidades brasileiras, sendo que as últimas reformulações têm atendido aos objetivos justificados pela ampliação da capacidade de atendimento do sistema, com vínculos nos mesmos termos, ou seja, produzir mais com menos, como veremos adiante.

Essa ampliação ocorre com duas medidas: por meio do REUNI, com a ampliação do número de vagas (o qual será apresentado com mais

\footnotetext{
3 Faremos, em seguida, uma análise em relação aos fundamentos do Programa Reuni, podendo, em alguns momentos, apresentar dados referentes a um caso concreto, o Reuni na Universidade Federal de Ouro Preto.
} 


\section{“EXPANSÃO PARA QUEM?": UMA ANÁLISE DOS OBJETIVOS DO REUNI E DAS DIRETRIZES PARA A EDUCAÇÃO DO BANCO MUNDIAL \\ Valéria Bonadia Marucchi Martoni}

detalhes na exemplificação da UFOP), e através da concessão ampliada da prestação de serviços educacionais às entidades privadas, conforme tabela abaixo.

\section{Tabela 1 - Matrículas na educação superior brasileira pública e privada}

\begin{tabular}{rrrr}
\hline Ano & $\begin{array}{l}\text { Matrículas } \\
\text { públicas }\end{array}$ & $\begin{array}{l}\text { Matrículas } \\
\text { privadas }\end{array}$ & $\begin{array}{l}\text { Total de } \\
\text { matrículas }\end{array}$ \\
\hline 2007 & 1.240 .968 & 3.639 .413 & 4.880 .381 \\
2008 & 1.273 .965 & 3.806 .091 & 5.080 .056 \\
2009 & 1.351 .168 & 3.764 .728 & 5.115 .896 \\
2010 & 1.461 .696 & 3.987 .424 & 5.449 .120 \\
\hline
\end{tabular}

Os dados do Censo da Educação Superior 2010 revelam o crescimento das matrículas e o aumento das vagas nas instituições federais no conjunto das universidades públicas, mas mesmo com esse crescimento, 73,17\% de todas as matrículas de graduação estão no setor privado, enquanto o setor público responde por $26,82 \%$. Conforme aponta Hopfer, “[...] para permitir o aumento real da taxa de escolarização, o Brasil promoveu a expansão do setor privado de ensino superior [...]" (2011, p. 44). O total de matrículas na educação superior de graduação no Brasil cresceu 10,43\% no período de um ano, crescimento que é atribuído aos ProUni, ao Programa Fies (Financiamento Estudantil) e ao REUNI.

Ainda de acordo com o Censo, em 2010, o Brasil contava com 2.377 instituições de ensino superior, das quais 278 eram públicas, sendo 99 do sistema federal, 108 estaduais e 71 municipais. No referido ano, o sistema público acolhia um total de 1.461 .696 matrículas de graduação, enquanto o setor privado compreendia 2.099 instituições, com 3.987.424 matrículas de graduação (INEP, 2011).

Com a política de crescimento das universidades públicas federais a reestruturação de suas atividades está voltada para a produtividade e competitividade, com sua consequente mercantilização. Nesse processo, as instituições públicas constituem-se em um campo propício ao empresariamento com vistas à obtenção de maior lucratividade. Tragtenberg já alertava sobre essa questão (1980, p.01):

[...] sob o capitalismo, ela [a Universidade] é obrigada pela lógica própria do novo sistema de exploração racional do trabalho, a recrutar grandes massas de indivíduos selecionados severamente para o provimento de cargos. Ela é a formadora dos 'recursos humanos' para a burocracia das empresas privadas e do Poder Público. [...] É uma fábrica que ao mesmo tempo produz um núcleo de intelectuais ligados às prebendas burocráticas da classe dominante e cria um novo exército 


\section{“EXPANSÃO PARA QUEM?": UMA ANÁLISE DOS OBJETIVOS DO REUNI E DAS DIRETRIZES PARA A EDUCAÇÃO DO BANCO MUNDIAL

industrial de reserva, uma camada intelectual proletaróide similar às massas subempregadas do sistema.

Não é difícil perceber essa lógica no cotidiano das universidades, onde docentes possuem cada vez mais metas de produção de artigos, participação em eventos, maior número de alunos em sala de aula e, consequentemente, de orientações. Com isso, distanciam-se das condições intelectuais e acabam seguindo os ditames do "produtivismo" acadêmico. E, esse movimento é reforçado pelo Reuni que, segundo as diretrizes gerais do programa, o decreto tem como meta global “[...] a elevação gradual da taxa de conclusão média dos cursos de graduação presenciais para noventa por cento e da relação de alunos de graduação em cursos presenciais por professor para dezoito, ao final de cinco anos, a contar do início de cada plano" (BRASIL, 2007). Segue-se a lógica do fazer mais com menos, do aumento da produtividade do trabalho do professor e, quando o quadro docente mostra a inexistência desse profissional para $o$ cumprimento da meta, há a possibilidade de alcança-la precarizando ainda mais as relações de trabalho por meio da contratação do Professor Equivalente.

As mudanças impostas pelo REUNI revelam a intensificação do trabalho no interior das universidades, conforme evidencia Chauí (2001a, p. 190):

\footnotetext{
Regida por contratos de gestão, avaliada por índices de produtividade, calculada para ser flexível, a universidade [...] está estruturada por estratégias e programas de eficácia organizacional e, portanto, pela particularidade e instabilidade dos meios e dos objetivos. Definida e estruturada por normas e padrões inteiramente alheios ao conhecimento e à formação intelectual, está pulverizada em micro organizações que ocupam seus docentes e curvam seus estudantes a exigências exteriores ao trabalho intelectual. A heteronomia da universidade autônoma é visível a olho nu: o aumento insano de horas-aula, a diminuição do tempo para mestrados e doutorados, a avaliação pela quantidade de publicações, colóquios e congressos, a multiplicação de comissões e relatórios, etc.
}

Ademais, uma nova atribuição foi designada aos professores permanentes, estabelecer uma comissão de acompanhamento do trajeto do estudante. Essa comissão tem como objetivo verificar as escolhas dos discentes ao longo do curso assegurando que este sai da universidade o mais rápido possível. Observamos, portanto, a lógica da diminuição do tempo nos bancos escolares, sugerida pelo BM. Com essa perspectiva, a concepção de processo educativo se reduz a frequentar aulas e ou realizar atividades complementares fora da universidade que possam ser validadas como créditos. A compreensão da vida universitária enquanto um processo de formação de um sujeito político - na concepção ampla do termo - segue sendo alijada desde a reforma efetuada no período da 


\section{“EXPANSÃO PARA QUEM?": UMA ANÁLISE DOS OBJETIVOS DO REUNI E DAS DIRETRIZES PARA A EDUCAÇÃO DO BANCO MUNDIAL \\ Valéria Bonadia Marucchi Martoni}

ditadura. Se naquele período, pensar e agir politicamente era uma ameaça à ordem estatal, um atentado contra o coletivo; no atual período, é apresentado como um atentado contra a carreira profissional do indivíduo. E assim, o período cujas experiências condicionam a postura que teremos frente ao mundo é determinado pela necessidade de compor o exército de reserva para o capital.

A dinâmica de produção capitalista se enraíza nesses espaços de produção do saber, tal como relatam Silva e Sguissardi (2001, p. 78):

[...] por um lado, mercadoriza-se ao extremo; por outro, na sua especificidade, acentua-se o movimento de redefinição da esfera pública, ao mesmo tempo em que se dissemina a crítica da antiga natureza dessa esfera e constroem-se os pilares de um novo espaço, em cujo centro se encontra a racionalidade da produção capitalista.

Ou seja, os mais diversos movimentos de reestruturações do ensino superior (com ênfase para o REUNI) têm como objetivo a reordenação desse 'espaço social' para o capital, seguindo, portanto, a lógica do mercado via redefinição das concepções do setor público e fusão com os interesses privados. (SILVA; SGUISSARDI, 2001).

Se, por um lado, o REUNI especificamente, reforça as políticas de acesso e permanência e estimula a interação da Universidade com as redes municipal e estadual de ensino, por outro, busca um aumento de vagas incompatível com a demanda superdimensionada, sendo, no quesito quantidade, totalmente insuficiente para fazer frente à realidade brasileira.

Além disso, temos que as verbas direcionadas ao programa estão condicionadas ao cumprimento de metas das já referidas (aumento em $20 \%$ de matriculas de graduação; aumento da taxa de conclusão; elevação da relação professor/aluno).

Essa "pactuação" para o aumento das vagas é expressa pelo governo:

Os planos de reestruturação apresentados pelas universidades federais, e aprovados pelo Ministério da Educação, terão sua exequibilidade financeira garantida pelo MEC a partir do ano de 2008, mediante termo de pactuação de metas a ser firmado entre o MEC e as universidades participantes (BRASIL, 2007).

O processo de adesão ao programa foi 'voluntário', através de decisões dos Conselhos Universitários, onde as respectivas IFES apresentaram um plano contendo as ações para se atingir as metas. Paralelamente ao referido programa, surgem as reações de resistência levadas à cabo por estudantes em diversas universidades em 2007, com manifestações, ocupações, protestos e confrontos com a polícia. De acordo com dados divulgados pelo Ministério da Educação, todas as 54 instituições federais de ensino superior aderiram ao REUNI, entretanto, nem todas aprovaram o programa pacífica ou democraticamente (MEC, 


\section{“EXPANSÃO PARA QUEM?": UMA ANÁLISE DOS OBJETIVOS DO REUNI E DAS DIRETRIZES PARA A EDUCAÇÃO DO BANCO MUNDIAL \\ Valéria Bonadia Marucchi Martoni}

2008). Tal como em outras universidades, na UFOP a adesão ao REUNI foi decidida democraticamente pelo Conselho Universitário, o qual é constituído por professores, alguns pró-reitores, discentes, técnicos, representante externo e de ex-alunos, além do reitor e vice-reitor ${ }^{4}$. Em relação ao chamado "ambiente democrático" onde são tomadas as decisões (os conselhos), é preciso tecer algumas ponderações.

Vejamos o caso da UFOP. O estatuto desta instituição, o qual norteia suas atividades e determina a composição dos órgãos colegiados superiores, não passou por reformulações significativas desde o governo ditatorial. Nesse sentido, pode-se apontar que o próprio conselho espelha uma estrutura que, em essência, é firmada estrategicamente para a manutenção do poder dos grupos que a assumem. Isso foi evidenciado em 2010 pelo "Observatório da UFOP”, publicação conjunta da Associação dos Docentes da UFOP, Sindicato dos Trabalhadores TécnicosAdministrativos da UFOP e Diretório Central dos Estudantes.

No referido jornal, tais entidades chamam a atenção para o fato de que o atual estatuto da Universidade "é da época da ditadura militar [sendo que] a última grande 'reforma' do mesmo não passou de adaptações obrigatórias à Lei de Diretrizes e Bases da Educação - LDB - [...], além de alguns remendos que são feitos de forma casuística" (OBSERVATÓRIO DA UFOP, 2010, p.02). Tal situação é mantida por questões estratégicas de poder e amparada pela retórica da democracia. $\mathrm{O}$ fato de essa manutenção ser estratégica fica evidente pelas possibilidades de reforma do estatuto elaboradas por representantes de toda a comunidade acadêmica por meio de um Congresso Estatuinte, o qual foi constituído em 1995. Ainda segundo o Observatório da UFOP (2010, P. 02), o estatuto que surgiria dessa proposta "modificava a estrutura de poder dos Conselhos, garantindo maior participação da comunidade universitária e acabando com a representação dos cargos de confiança da administração dentro do CUNI".

Fica claro que esta reforma iria interferir diretamente no núcleo do poder real, mas a sua não aprovação se embasou na Lei 9192 de 1995, a qual trata do processo de escolha dos dirigentes universitários. Conforme

\footnotetext{
${ }^{4}$ Vale lembrar aqui que se segue sem a democracia apontada como necessária por Maurício Tragtenberg em "Os caminhos da democratização da Universidade". O autor cita que: "[...] Uma das reivindicações presentes na Universidade é a da autonomia universitária e da participação paritária nos órgãos decisórios em todos os níveis, englobado professores, estudantes e funcionários, a real 'comunidade acadêmica'. [...] A universidade democrática inexiste sem participação paritária estudantil. [...] O campus não se restringe à sala de aula; as habitações e o conjunto de ruas do campus fazem parte do regime de autonomia universitária. A autonomia universitária - incluindo a financeira - não é uma via de democratização, é a condição prévia para conseguila. Não é um fim em si, é um meio que pode ou não ter eficiência, para que as universidades cumpram seu papel. [...] Autonomia plena, gratuidade do ensino, publicidade dos atos administrativos e representação paritária de funcionários, alunos e professores são as pré-condições da democracia universitária. Ela porém não deve confinar-se ao campus; de nada vale se a autonomia e liberdade sindical, ampla liberdade de pensamento e expressão não a complementarem" (TRAGTENBERG, 2004, p. 95-98).
} 


\section{“EXPANSÃO PARA QUEM?": UMA ANÁLISE DOS OBJETIVOS DO REUNI E DAS DIRETRIZES PARA A EDUCAÇÃO DO BANCO MUNDIAL

a referida Lei, os órgãos colegiados superiores precisam representar a comunidade universitária, mas devem contar com "o mínimo de setenta por cento de membros do corpo docente no total de sua composição" (BRASIL 1995), praticamente desprezando os técnicos e os discentes. $\mathrm{Na}$ UFOP, a existência de somente uma aparência democrática é evidenciada pelo Observatório da UFOP (2010, p.02): “os conselhos, não representam de fato a comunidade universitária, pois são majoritariamente compostos por docentes, os pró-reitores que são cargos de confiança do reitor, são indicados pelo mesmo [e, portanto] não são eleitos pela comunidade universitária [...]. No CUNI [Conselho Universitário], os discentes tem apenas dois representantes e os técnicos administrativos apensa um [...]" (OBSERVATÓRIO DA UFOP, 2010, p.02). Ao se analisar os assentos do CUNI, verifica-se de fato que seis conselheiros recebem cargo de direção, sendo, portanto, indicados pelo reitor e vice.

Em relação à representatividade dos técnicos (apenas um), esta é colocada de forma igualitária ao representante da comunidade, o qual, neste conselho, deve ser indicado pela Federação das Indústrias do Estado de Minas Gerais, ou seja, não se trata de um porta-voz da comunidade, mas dos grupos empresariais regionais. Isso posto, é preciso relativizar que os encaminhamentos do REUNI foram anteriormente discutidos e democraticamente deliberados via conselhos universitários, mesmo porque fica evidente que as disputas mais acirradas não são colocadas nesses órgãos, mas anteriormente, ou seja, na definição dos assentos dos conselheiros. Trata-se de uma obviedade que houve debates nas universidades, mas a decisão final se restringiu a uma estrutura que propicia poder ao grupo que a domina, ou seja, um órgão que filtrou o que era conveniente não a toda comunidade, mas a uma fração desta, a qual é representativa dos interesses do Ministério da Educação.

Perante esse ambiente "democrático", a aprovação do REUNI gerou vários protestos e manifestações em diversas instituições, conforme mencionado. Paralelamente, a entidade máxima de representação estudantil, a UNE, acabou enfraquecendo ${ }^{5}$ as reivindicações nas universidades ao apoiar o programa diante do aumento de vagas, sem discutir mais pormenorizadamente a questão qualitativa do ensino.

Inicialmente, a União Nacional dos Estudantes foi contra as diretrizes do REUNI que objetivavam a "diversificação das modalidades de graduação, preferencialmente não voltadas à profissionalização precoce $\mathrm{e}$ especializada" (inciso IV do $2^{\circ}$ parágrafo), a qual preconiza a criação de cursos profissionalizantes e técnicos. Mas, diante da luta pela ampliação do acesso e permanência dos estudantes nas instituições públicas e com as

\footnotetext{
${ }^{5}$ Nota-se aqui que com a esquerda no poder, os principais movimentos de massa e certas organizações representativas enfraquecem suas reivindicações. Esse desengajamento dos movimentos sociais paralelamente abre espaço para a organização da oposição 'de esquerda', passando a apoiar os programas e comportamentos governistas, ou seja, nesse contexto os movimentos sociais "[...] deixam de ser fiscalizadores do Estado e passam a ser executores de políticas públicas" (COIMBRA, 2010, p. 01).
} 


\section{“EXPANSÃO PARA QUEM?": UMA ANÁLISE DOS OBJETIVOS DO REUNI E DAS DIRETRIZES PARA A EDUCAÇÃO DO BANCO MUNDIAL \\ Valéria Bonadia Marucchi Martoni}

ressalvas publicadas na resolução acima, a UNE manifesta seu apoio ao REUNI, que se apresenta como um instrumento de avanço na conquista da organização.

Seguindo as diretrizes do BM, as proposições do REUNI aparentemente são consideradas positivas, pois oferecerem um maior número de vagas, redução da evasão, melhora na estrutura universitária, as quais são direitos de toda a sociedade (direitos do trabalhador, uma vez que também é necessidade do capital). Porém, é preciso atenção se realmente as reformas melhoram efetivamente o quadro ou se somente estão orientadas a obtenção do aumento dos índices quantitativos, pois a melhoria dos indicadores faz-se necessária para que o país torne-se mais competitivo em termos de contingente de força de trabalho, oferecendo vantagens aos processos de reprodução do capital com vistas a aumentar os seus patamares de acumulação.

Segundo Correia (2008, p. 04):

[...] é de se considerar que os propósitos do REUNI até podem ser viáveis. Porém, se não houver um redirecionamento no uso dos recursos públicos para bancar as atividades de expansão que ele assume, corremos o risco de ver o REUNI cair na conta daqueles projetos que, ainda que bem pensados e intencionados, nada puderam alcançar porque, paralelo a eles, o Estado se fez indiferente aos direitos sociais.

A colocação de Correia (2008) destaca a necessidade de atenção aos programas efetivados nas instituições superiores que aderiram ao REUNI, considerando que é preciso averiguar a existência ou não de uma canalização do fundo público para a manutenção dessa expansão. Contudo, as movimentações contrárias ao programa da forma como foi instituído, já apontavam o foco do governo na questão quantitativa, ou seja, a priorização da abertura de vagas mediante o comprometimento da qualidade do ensino. Além disso, é preciso relativizar a viabilidade dos "propósitos do REUNI" desde que exista um direcionamento efetivo de recursos públicos ao programa, uma vez que a sua formulação e execução não ocorreram como ato de rompimento com os interesses do capital no âmbito da educação superior, o que fica evidente pelas políticas públicas que favorecem o empresariamento da educação e as contra-partidas das IFES exigidas pelo governo para o recebimento de recursos.

\section{Considerações Finais}

O Banco Mundial estipula prioridades aos programas e projetos para que possam ampliar o ensino público e privado, sendo que, para o atendimento dessas diretrizes, faz-se necessária a diversificação das instituições de ensino, além da necessidade do desenvolvimento de pesquisas em áreas que apresentem maior vantagem comparativa para 


\section{“EXPANSÃO PARA QUEM?": UMA ANÁLISE DOS OBJETIVOS DO REUNI E DAS DIRETRIZES PARA A EDUCAÇÃO DO BANCO MUNDIAL \\ Valéria Bonadia Marucchi Martoni}

empresas privadas em atuação em uma determinada região, podendo garantir aos países centrais melhores vantagens nas relações comerciais.

A análise de alguns documentos do Banco Mundial evidenciou que a educação representa um campo lucrativo para exploração de acordo com os interesses do capital. Trata-se de um grupo de capitalistas gerando lucro ao formar trabalhadores que produzem ou produzirão mais valor a outros grupos de capitalistas. Conforme discussão sobre a intensificação do trabalho, a dinâmica do capitalismo “[...] no processo da sua mundialização, não resultou apenas na criação do maior contingente histórico de desempregados, subempregados e empregados precarizados e na exponenciação da 'questão social' [...]" (NETTO; BRAZ, 2008, p. 237) resultou fundamentalmente de uma relação social característica, que exige a dominação de uma classe e a subordinação de outra e um processo de contínua concorrência, a da mercantilização da força de trabalho.

Tendo em vista que: 1) os processos educacionais estão atrelados às demandas de determinadas qualidades da força de trabalho em função da base tecnológica hegemônica utilizada no setor produtivo; e 2) que a demanda não é apenas pela qualidade, mas também que esta seja ofertada de forma abundante para a permanência do movimento de acumulação do capital, constatamos que as propostas governamentais submetem-se aos ditames do sistema, da qual é exemplo a ampliação de estruturas para possibilitar o ingresso de contingentes maiores de estudantes nas salas de aula, como uma prática operacionalizada diante das imposições da racionalidade econômica vigente, como é o caso do Reuni.

A reestruturação das Instituições Federais de Ensino Superior (IFES) é uma necessidade, contudo, os planos elaborados e encaminhados pelas IFES ao Ministério da Educação, ao serem firmados de acordo com as metas quantitativas do REUNI, podem comprometer a formação qualitativa. Segundo Frigoto (1995, p.36): “[...] a questão não é de se negar o progresso técnico, o avanço do conhecimento, os processos educativos e de qualificação ou simplesmente fixar-se no plano das perspectivas de resistência [...] mas de disputar concretamente o controle hegemônico do progresso técnico, do avanço do conhecimento e da qualificação".

Diante das referidas reformas e processos, vemos que facilmente atendem aos interesses do setor produtivo e políticos dominantes, decompondo a formação integral do ser humano, afinal, como destaca Tragtenberg (2004, p. 204) “[...] a educação não pode estar acima da estrutura socioeconômica que a determina". A partir de um estudo referente às políticas públicas educacionais, o objetivo é demonstrar que o sistema de ensino superior está orientado em uma única direção, com o discurso exclusivo de que podem se tornar meios importantes para o desenvolvimento econômico.

O ensino passa por um processo de adequação aos novos padrões, onde o objetivo são os melhores índices e rankings internacionais para melhorar o crescimento econômico (LIMA, 2011) fazendo-se necessário o 


\section{“EXPANSÃO PARA QUEM?": UMA ANÁLISE DOS OBJETIVOS DO REUNI E DAS DIRETRIZES PARA A EDUCAÇÃO DO BANCO MUNDIAL \\ Valéria Bonadia Marucchi Martoni}

desenvolvimento de habilidades e competências para o mercado de trabalho. Ou seja, a 'empregabilidade' é o princípio e o desígnio de padronização da escola, sua organização e sua pedagogia. A escola tornase gradualmente um sistema hierárquico de empresas produtoras de "capital humano" a serviço da "economia do conhecimento", onde as pessoas passam a ser incorporadas pela máquina econômica.

O foco na formação operacional voltada à preparação de mão de obra para o mercado - ao invés daquela humanística, necessária à criação de possibilidades para a superação da auto-alienação do trabalho, se traduz em um exemplo concreto de política pública que atende a setores específicos empresariais e mantêm a ordem vigente, uma vez que reduz as possibilidades de questionamento, ao mesmo tempo em que reproduz a ideia de que a formação técnica é a única forma de garantir a reprodução da existência justamente por ser a que permite a venda da força de trabalho. Assim, tal forma histórica de sociabilidade torna-se naturalizada e a liberdade de opção entre alternativas é comprometida pelo próprio modelo educacional, o qual é um forte mantenedor da ordem vigente por não fornecer os meios que explicitem os elementos causadores de suas contradições.

Com as políticas de reformulações da educação superior realizada nos governos Collor, ampliada nos primeiros anos de Fernando Henrique Cardoso e continuadas com Lula, ocorreram parcerias publico privadas e abertura do setor educacional para grupos e empreendimentos estrangeiros, com o crescimento do ensino superior privado e baixos recursos destinados à esfera pública, embora o último tenha realizado um repasse significativo se comparado aos presidentes anteriores, essa verba ainda encontra-se aquém de atender a demanda nacional com a qualidade necessária, seja ao que se refere a permanência do estudante, seja ao que se refere às condições de trabalho de docentes e técnicos.

As políticas públicas, portanto, são orientadas ao atendimento das diretrizes dos órgãos supraestatais que visam a ampliação da internacionalização produtiva e financeira. E as instituições de ensino superior devem estar baseadas na produção de conhecimento e estratégias voltadas ao crescimento econômico, para a formação de uma "força de trabalho qualificada e adaptável" (BANCO MUNDIAL, 2002, p. 20).

Diante de um padrão de dependência de desenvolvimento econômico e seguindo os ditames da burguesia nacional e internacional, verificamos que as reformulações na educação superior não só mantém como também tornam ainda mais profundas as dependências. Ou seja, o Programa de Reestruturação e expansão das Universidades Federais implementado no governo Lula "[...] esta inserido em um processo muito mais amplo de reordenamento do Estado capitalista, considerando como uma das principais estratégias da burguesia internacional para o enfrentamento da crise estrutural do capital" (LIMA, 2007, p. 186). Em suma, o programa, em sua pseudoconcreticidade, se apresenta como uma política social de 
ampliação do acesso ao ensino público, porém, após as análises empreendidas, verifica-se que este se pautou pelos ditames do capital, expressas nas diretrizes do BM, o que demonstra que tal expansão não deixou de promover o direcionamento do fundo público para a lógica reprodutiva do capital.

Considerando que a realidade social é pautada por um movimento ininterrupto a partir de diferentes posicionamentos e ações levadas a cabo pela luta de classes, é preciso salientar que os desdobramentos do REUNI ainda estão em curso, ou seja, se os elementos contrários a tal programa podem ser verificados e apontadas as suas possíveis repercussões via análise orientada pela Dialética do Materialismo Histórico, deve-se salientar que a aproximação é sempre provisória, fato este que demonstra a necessidade do desenvolvimento de novas pesquisas.

\section{Referências}

ANDES, 2007. PDE - O plano de desestruturação da educação superior. Disponível em: <http://www.adufrj.org.br/observatorio/wpcontent/uploads/2009/08/cartilhaPDE.pdf.> Acesso em: 24 mar. 2011.

BANCO MUNDIAL. Constructing knowledge societies: new challenges for tertiary education. 2002. Disponível em: <http://www.bancomundial.org.br>. Acesso em: 28 nov. 2011.

BANCO MUNDIAL. Aprendizagem para Todos. Estratégia 2020 para a Educação do Grupo Banco Mundial. RESUMO EXECUTIVO, 2011. Disponível em: <www.worldbank.org/educationstrategy2020> Acesso em: 29 nov. 2011.

BRASIL. Lei 9192 de 21 de dezembro de 1995. Altera dispositivos da Lei $\mathrm{n}^{\mathrm{o}} \underline{5.540}$, de 28 de novembro de 1968, que regulamentam o processo de escolha dos dirigentes universitários. Disponível em: http:/ / www.jusbrasil.com.br. Acesso em: 24 fev 2012.

BRASIL. Lei $\mathrm{n}^{\circ}$ 9.394, de 20 de dezembro de 1996. Estabelece as diretrizes e bases da educação nacional. Disponível em:< http://portal.mec.gov.br/seed/arquivos/pdf/ tvescola/leis/lein9394.pdf> Acesso em 12 mai 2012.

BRASIL. Ministério da Educação. Decreto n 6096, de 24 de abril de 2007 que institui o Programa de Apoio a Planos de Reestruturação e Expansão das Universidades Federais - REUNI. Disponível em: <HTTP://www.planalto.gov.br/ccivil_03>. Acesso em 28 out. 2011. 
BRASIL. Ministério da Educação e Ministério do Planejamento, Orçamento e Gestão. Portarias Interministeriais n. 22 e 224. Disponível em: <http://www.adunb.org/ portaria_interministerial22. pdf> Acesso em 08 jan. 2012.

CATANI, Afrânio Mendes. A educação superior. In: OLIVEIRA, Romualdo Portela de; ADRIAO, Theresa (Orgs.). Organização do ensino no Brasil: níveis e modalidades na Constituição Federal e na LDB. São Paulo: Xamã, 2002.

CHAUÍ, Marilena. Escritos sobre a universidade. São Paulo: Unesp, 2001a.

CHAUÍ, Marilena. O que é ideologia? São Paulo: Brasiliense, 2001 b.

CHESNAIS, François. A mundialização do capital. (Tradução de Silvana Finzi Foá). São Paulo: Xamã, 1996.

CORBETTA. Piergiorgio. Metodología y Técnicas de Investigación Social. Madridd: Mc Graw Hill, 2007.

CORREIA, Wilson. REUNI: vamos continuar calados? Revista Espaço Acadêmico, n. 82, p. 1-5, março de 2008. Disponível em: < http:/ / www.espacoacademico.com.br/082/82correia.pdf $>$. Acesso em: 27 nov. 2011.

CUNHA, Luiz Antônio; GÓES, Moacyr de. O Golpe na Educação. Rio de Janeiro: Zahar Editores, 2002.

DANGEVILLE, Roger (org.). Karl Marx e Friedrich Engels: critica da educação e do ensino. Lisboa: Moraes, 1978.

OBSERVATÓRIO DA UFOP. ESTATUTO DA UFOP: reforma urgente e necessária. Ouro Preto, 2010, n. 01, Ano 1, p. 02.

FARIA, José Henrique de. Materialismo Histórico e Estudos Interdisciplinares. Curitiba: EPPEO, 2011.

FRIGOTTO, Gaudêncio e outros. Neoliberalismo, Qualidade Total e Educação. Petrópolis. RJ: Vozes, 1995.

HARVEY, David. A condição pós-moderna: uma pesquisa sobre as origens da mudança cultural. (Tradução de Adail Ubirajara Sobral e Maria Stela Gonçalves). São Paulo: Loyola, 1992.

HOPFER, Kátia Regina. Estado capitalista e estratégias de gestão de instituições de Ensino Superior privadas: o PROUNI como política social 
e como asseguramento da acumulação do capital. 2011. 133f. Tese (Doutorado em Administração)- Universidade Federal do Paraná, Setor de

Ciências Sociais Aplicadas, Programa de Pós-Graduação em Administração. Curitiba, 2011. Disponível em: <http://dspace.c3sl.ufpr.br/dspace/bits tream/handle/1884/26461/HOPFER,\%20Katia\%20Regina\%20Tese\%20de \%20Doutorado\%202011.pdf?sequence=1> Acesso em 20 out 2011.

LEHER, Roberto; LOPES, Alessandra de Barros Piedras. Trabalho docente, carreira, autonomia universitária e mercantilização da educação. In D. MANCEBO; J. R. SILVA JÚNIOR; J. F. OLIVEIRA (Orgs.), Reformas e Políticas: Educação Superior e Pós-graduação no Brasil. São Paulo: Alínea, 2008.

LIMA, Kátia Regina de Souza. Reforma da Educação Superior nos anos de contrarevolução neoliberal: de Fernando Henrique Cardoso a Luís Inácio Lula da Silva. 2005. 462f. Tese (Doutorado em Educação). Programa de Pós-Graduação em Educação da Universidade Federal Fluminense. Niterói, 2005.

LIMA, Kátia. As novas faces da intensificação do trabalho docente no Brasil. In: Encontro Brasileiro de Educação e Marxismo, 5, 2011. Florianópolis-SC. Anais... Florianópolis, 2011. Disponível em: <http://www.5ebem.ufsc.br/trabalhos/eixo_09/e09d_t002.pdf>. Acesso em: 07 dez 2011.

MARX, Karl. Manuscritos econômico-filosóficos e outros textos escolhidos (tradução de José Carlos Bruni, et. al.) 4.ed. São Paulo: Nova Cultural, 1987 (Coleção Os pensadores).

MARX, Karl; ENGELS, Friedrich. A Ideologia Alemã. São Paulo: Boitempo, 2007.

MARX, Karl. O capital: crítica da economia política, livro I, volume I. Tradução de Reginaldo Sant'Anna. 26.ed. Rio de Janeiro: Civilização Brasileira, 2008.

MARX, Karl; ENGELS; Friedrich. Manifesto do Partido Comunista. Tradução de Antônio Carlos Braga. São Paulo: Editora Escala, 2009.

MEC - Ministério da educação. REUNI - Diretrizes Gerais. 2007. Disponível em: <portal.mec.gov.br/sesu/arquivos/pdf/diretrizesreuni.pdf> Acesso em 28 fev 2011. 
MÉSZÁROS, István. A educação para além do capital. 2 ed. São Paulo: Boitempo, 2008.

NETTO, José Paulo; BRAZ, Marcelo. Economia política: uma introdução crítica. 4.ed. São Paulo: Cortez, 2008.

SAVIANI, Demerval; SANFELICE, José Luís; LOMBARDI, José Claudinei (orgs.). Capitalismo, trabalho e educação. 3ed. Campinas: Autores Associados, HISTEDBR, 2005. (Coleção educação contemporânea).

SGUISSARDI, Valdemar. Universidade no Brasil: dos modelos clássicos aos modelos de ocasião. In: MOROSINI, M. (Org.) A universidade no Brasil: concepções e modelos. Brasília, DF: Inep, 2006.

SILVA JR., João dos Reis; SGUISSARDI, Novas faces da educação superior no Brasil: reformas do estado e mudanças na produção. 2. ed. São Paulo: Cortez; Bragança Paulista, SP: USF-IFAN, 2001.

SILVA, Maria Abádia. Políticas para a educação pública: a intervenção das instituições financeiras internacionais e o consentimento nacional. 1999. 327f. Tese (Doutorado em Educação). Programa de Pós-Graduação em Educação. Faculdade de Educação, Universidade Estadual de Campinas, Campinas, 1999. Disponível em: < http://www.scielo.br/pdf/ccedes/v23n61/a03v2361.pdf>. Acesso em 04 mai. 2012.

TRAGTENBERG, Maurício. Burocracia e Ideologia. São Paulo: UNESP, 2006.

TRAGTENBERG, Maurício. Sobre educação, política e sindicalismo. São Paulo: UNESP, 2004. 